\title{
Innovative Fuel Energy Saving Practices among the Small Farming Households, Ethiopia
}

\author{
Yohannes Gebre Michael \\ Department of Geography and Environmental Studies, Addis Ababa University, P.O. Box 33569, Addis Ababa, Ethiopia
}

\begin{abstract}
Many studies have indicated that traditional cooking stoves are inefficient and their use leads to the acceleration of deforestation, the decline of land productivity, subsequently triggering climate changes and human health problems. On the other hand, the introduced "improved cooking stoves" also have their own disadvantages. Therefore, the case study was conducted aiming to study the rationale of using traditional stoves and document the innovative biomass energy saving practices of the community. The research studied two pilot areas in rural community with different agro-ecology and farming systems. Moreover, individual and focus group discussions were conducted among women households using transect and random sampling. The findings indicate that use of traditional stoves is dominant practice due to flexibility, simplicity and multi-functionality. Moreover, the biomass fuel use is integral part of the farming system, socio-cultural framework and habits and customs of local community. The study has documented local innovation practices of biomass energy saving by improving stoves and chimney, combining different crops in food cooking, improving local beer processing, shifting crop-land to woodland. Moreover, the study reveals that the enclosure of communal forests due to the modern extension services is attributed with long distance travel to collect fuel wood, leading to conflicts and declines livelihood diversity of the poor population. Hence, consideration of local initiatives in development of appropriate and sustainable technology is essential.
\end{abstract}

Key words: Traditional stove, improved stove, local innovation, appropriate technology, sustainability.

\section{Introduction}

Today, globally more than three billion people are using biomass fuel and traditional stoves for cooking and heating in their homes. Most of them are from developing countries of Africa, Asia and Latin America [1]. Similarly, in Sub-Saharan Africa, biomass fuel is the bases of livelihoods for more than $80 \%$ of the population. In Ethiopia, more than $95 \%$ of the population depends on biomass fuels, such as firewood, dung and agricultural residues for cooking, lighting and heating [2], which is one of the highest in Africa.

Many studies have indicated that the biomass energy and traditional open stoves have a big impact on human health problem. They are accelerating deforestation and climate change, declining land productivity and triggering the vicious circle of

Corresponding author: Yohannes Gebre Michael, Ph.D., research field: geography. poverty [3-6]. Therefore, an efficient and effective use of biomass energy is assumed to address the six of eight millennium development goals (MDGs), including food security, accessing social services, empowering women and assuring sustainable use of resources [7, 8]. Similarly, the promoters of improved cooking stove argue to provide the triple benefit of health, preservation of local eco-system and reducing gas emission [3].

Different initiatives have been introduced at international, national and local levels. The Global Alliance for Clean Cookstove (GACC), Africa Clean Cooking Energy Solutions Initiative (ACCES) and World Bank initiate Africa clean cooking energy solutions and United Nations convention to combat desertification. Similarly, as a component of the national carbon resilient green economy plan of Ethiopia, 100 million improved cooking stove will be distributed by 2020. The distributed stoves have a capacity of saving up to $75 \%$ of biomass energy [2]. 
Unfortunately, the adoption of improved cooking stove at global level even with incentives (free training and distribution of improved stoves) is minimal or not sufficient. Wide range of factors have been highlighted related to the low adoption rates, such as availability, collection cost, fuel prices and household income, education and awareness, family size, gender and socio-cultural differences [9-14].

Generally, the review of improved cooking stove has the following major fundamental gaps. First, prior to introduction of the new technology, documentation of the functions of traditional stove under local conditions was not performed. Secondly, the improved cooking stove is transferring standard technology from outsiders (developers of technology) to local community (receiver). Moreover, the new technology offers replacement or substitutions of the traditional stoves without understanding why do the community continue to use traditional stoves? Thirdly, no attempt was made to understand and document the experimentation and innovative competence of the community for efficient use of biomass fuel and minimizing the smoke. Moreover, it emphasizes on technical efficiency rather than understanding of the interface between the different land use/covers in the framework of biomass fuel use and sustainability. Fourthly, no attempt is made to understand how community is vulnerable to the inefficient use of biomass energy by external interventions. Fifthly, there is no feedback mechanism to improve the standard technology, so that they could fit to heterogeneous community needs and priorities during the diffusion process. And lastly, diffusion of the technology is usually attached with incentives and project cycle evaluations with less attention to sustainability. In other words, the technology transfer in the name of "improved" technology might be attributed to paralyzing the community competence to experiment and to innovate in solving their own problems. This also triggers dependency syndrome as the expense of community values and identities.
The case study is conducted to study the rationale of using traditional stoves and document the innovative biomass energy saving practices of the community.

\section{Materials and Methods}

The case study is conducted in two rural community pilot areas of Ethiopia with different agro-ecology and farming practices. The first pilot area in Ensarao district, specifically Salayish kebele has oxen plough with cereal production, in the Amhara region about $140 \mathrm{~km}$ North-West of Addis. The second pilot area Doketu kebele has dry lowland with hoe culture and agro-forestry, in Konso special woreda in the Rift Valley of South-Western Ethiopia.

Totally 110 women are questioned in the individual and group discussions in both pilot areas. About 60 women are from Doketu and 50 from Salayish. The individual and group discussions are made randomly on transect method to cover different land uses and covers and wealth rank groups. Accordingly, who ever meet during the transect walk are consulted with the help of checklist. The study was complemented with the observation of household stove uses.

\section{Profile of the Study Area}

In both pilot areas, the cultivated land is the major land use type (around 67\%) and the communal forest area also covers up to $20 \%$ (Table 1) of total area. Based on the group discussions and reflection from the development agents at kebele level, there is an expansion of cultivated area and settlements with the colonization of communal forest and grazing lands. The family size of a household varies across the pilot areas, and average family size is six and four persons for Salayish and Doketu, respectively. The family size also varies between different wealth rank groups, and the big family size is skewed to the better-off (Table 2). Similarly, land holding among the households is unevenly distributed between the pilot areas and within different wealth rank groups. Large and the better-off farmers have larger farm sizes and more 
Table 1 Land use and cover of the two pilot areas.

\begin{tabular}{lll}
\hline \multirow{2}{*}{ Land use } & \multicolumn{2}{c}{ Cover area (\%) } \\
\cline { 2 - 3 } & Doketu & Salayish \\
\hline Cultivated land & 60 & 67 \\
Grazing land & 5 & 10 \\
Forest area & 20 & 10 \\
Badlands (rook outcropped) & 5 & 7 \\
Settlements & 5 & 3 \\
Others & 5 & 3 \\
\hline
\end{tabular}

Table 2 Family size of the sample population.

\begin{tabular}{|c|c|c|c|c|}
\hline \multirow{3}{*}{$\begin{array}{l}\text { Category of } \\
\text { household }\end{array}$} & \multicolumn{4}{|c|}{ Family size (number) } \\
\hline & \multicolumn{2}{|c|}{ Doketu } & \multicolumn{2}{|c|}{ Salayish } \\
\hline & Average & SD & Average & SD \\
\hline Better-off & 8.7 & 3.0 & 4.3 & 1.4 \\
\hline Medium & 6.2 & 2.5 & 4.8 & 1.9 \\
\hline Poor & 5.9 & 2.3 & 5.0 & 2.2 \\
\hline Woman-headed & 3.9 & 1.7 & 2.6 & 1.2 \\
\hline Average & 6.2 & & 4.2 & \\
\hline
\end{tabular}

fragmented plots than the poor farmers. The average land holding is 0.5 ha in Doketu and 1.0 ha in Salayish. In pilot areas, both farming and livestock rearing are the bases of livelihoods. Moreover, some of the farmers complement their livelihoods with petty trade, craft work, daily labor and productive safety net program run by the government.

\section{Results}

Usually, the traditional stoves are embedded in the land use and socio-cultural settings of the community as indicated below.

\subsection{Management and Utilization of Communal Resources}

Traditionally, the communal grazing lands and woodland in the pilot areas are managed by the grassroots institutions. The elders with deep rooted knowledge and experience play fundamental role in the management of the common resources. For example, in the use of communal grazing land, there are seasons when it is open to specific livestock (oxen and mules, horses and young cattle) and they are totally enclosed during the rainy seasons. Similarly, the communal forest in the rural contest have multiple functions as source of fuel wood and pasture, beekeeping, source of traditional medicine, centre of ritual and as indicators of traditional early warning systems. Accordingly, in Konso or Doketu, any misuse of the natural resources is supervised by the locally elected village groups known as Korshata. The communal forest is also serving as centre of rituals, when the rains failed and/or human and livestock diseases breakout, the community pray for good season under the leadership of the elders known as Kata. Similarly, the common forests with their biodiversity are serving as source of traditional medicine for human and livestock by the traditional healers known as Harmota.

A wide range of annual and perennial plants, including trees, bushes and weeds, are used as indicators of bad or good seasons in Konso. For example, when the Moringa tree remains green and has some moisture around its roots, when some local cactus plants have flowers, when a weed locally known as Shoryta is flowering, while the desert rose (Kulbakolta) often used to demarcate plot boundaries is flowering, or when some wild fruit trees such as Leppo-leyeshu (Latin name) bear a lot of fruits during a specific season, these are indications of a good rainy season.

Unfortunately, due to the continuous marginalization of the customary institutions by the development agents and kebele leaders, the sustainable use of resources has been challenged.

\subsection{Packages of Traditional Stoves}

The traditional stove in the rural context has a complex and diverse functions, and any minor changes without deep understating the problem might have many undesired outcomes. Accordingly, the different packages of using traditional stoves are highlighted.

\subsubsection{Source of Fuel}

The fuel materials include branches of trees and bushes, leaves, maize and sorghum straws and cow 
dung (Table 3 and Fig. 1), while in Konso, the community uses more dominant wood, under the agro-forester and hoe farming practices. The collection is usually combined with farming activities, such as hoeing, weeding, guarding from wild life, harvesting and keeping livestock with division of labour in the household. Generally, the highest consumers of fuel wood in the community are craft people and the better-off with big family size, while the poor families make their living from wood sale. Similarly, the consumption of fuel wood is higher during rainy season, periodic market days, prolonged drought and marriage ceremony and holidays.

Table 3 Source of energy for consumption and sell in Salayish kebele.

\begin{tabular}{llll}
\hline \multirow{2}{*}{ Wealth category } & \multicolumn{3}{c}{ Source of fuel (\%) } \\
\cline { 2 - 4 } & Wood & Cow dung & Straw of crops \\
\hline Better-off & 53 & 41 & 6 \\
Medium & 45 & 43 & 12 \\
Poor & 46 & 39 & 15 \\
Women head & 50 & 38 & 12 \\
\hline
\end{tabular}
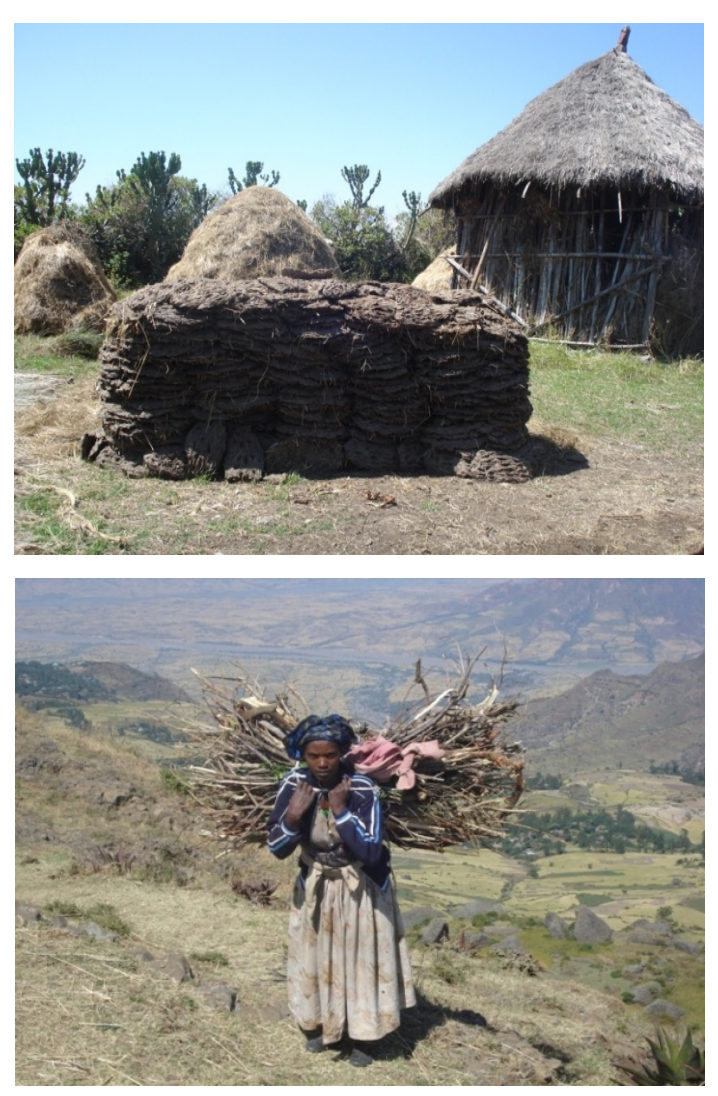

Fig. 1 Different sources of fuel.

\subsubsection{Access to Fuel}

Major source of fuel for the majority of the population is the communal forest land, and some use is from the private land, mainly Eucalyptus trees as in the case of Salayish. However, in Doketu, both communal and private lands are major source of fuel wood. Generally, in both pilot areas, the size of communal forest areas is declining due to expansion of farming and settlements and enclosures under the agricultural extension system.

Under the agro-forestry of Konso, multipurpose woody species include fruit trees (papaya, banana, avocado), stimulants (coffee and chat), Moringa stenopetala, Ficus vasta, Cordia africana and Terminalia brownill, Moringa stenopetala, locally known as Shelqata which is a staple food and the fresh leaves of which are used as a kind of "cabbage" in the daily meals of the Konso. In addition, it serves as fodder crop (also for sale), for fuel, medicinal purposes and water purification. Some farmers use their trees on the plot as collateral to acquire informal credit and savings.

\subsubsection{Food Habits}

Both pilot communities have different patterns and traditions of food and drinks preparations. Salayish community is dominantly orthodox Christians, where they observe different saint days and ceremonies with preparation of local drinks and food (bread and injera as stable food). Boiled legumes and roasted grains are also customary in the food culture. Similarly, in Doketu or Konso culture, the stable food is Quarkufa made from flour of sorghum and Moringa leaves, and Cheka-local beer made from sorghum or maize. Both serve as traditional food and drinks during group work of farming activities. Tea and coffee are also prepared with their respective cultures. For example the local beer Areke made from sorghum or maize needs a distillation process and consumes relatively high amount of fuel wood.

\subsubsection{House Design}

In both pilot areas, cottage and corrugated iron 
made houses are common. The traditional cottage houses covered with grass accounts 30\%-40\%. The corrugated iron made houses are used to be sign of economic status and modernization. Moreover, the modern corrugated iron has windows with a better air circulation. However, today the corrugated iron made houses are less expensive than grass made cottages. The corrugated iron is very warm during day and cold during nights, and demands more energy to warm than the traditional one. Due to the availability of health extension service in all rural areas, most of the households are influenced to separate their living room and kitchen houses. However, most of them also have additional traditional stove at home for cooking, warming and lighting.

\subsubsection{Spatial Location of Traditional Stoves}

Generally, the traditional stoves are made from three stones, usually basalt stone, and some collect from river beds due to smooth surface and others use small clay. The three stones can be easily adjusted to the different size of utensils, food varieties and fuel types. Usually, the indoor traditional stove is located in the centre to serve cooking, warming and lighting. However, stove for baking Ingera, is located in the corner with small holes or chimney attached outdoor. Traditional stove is also a rule than an exception in any household in the community.

\subsubsection{Functions}

Generally, the traditional stove in the rural context has triple functions of cooking, warming and lighting in absence of electricity supply (Fig. 2). For the combined functions, they are usually used dry wood with minimal smoking. The ash from the traditional stove is used also as fertilizer around the homestead.

\subsection{Vulnerability to Inefficient Fuel Energy Use}

Usually, rural communities are claimed that their practices of traditional stoves are inefficient in fuel use and they are the main reasons of deforestation and land degradations. However, there are also external
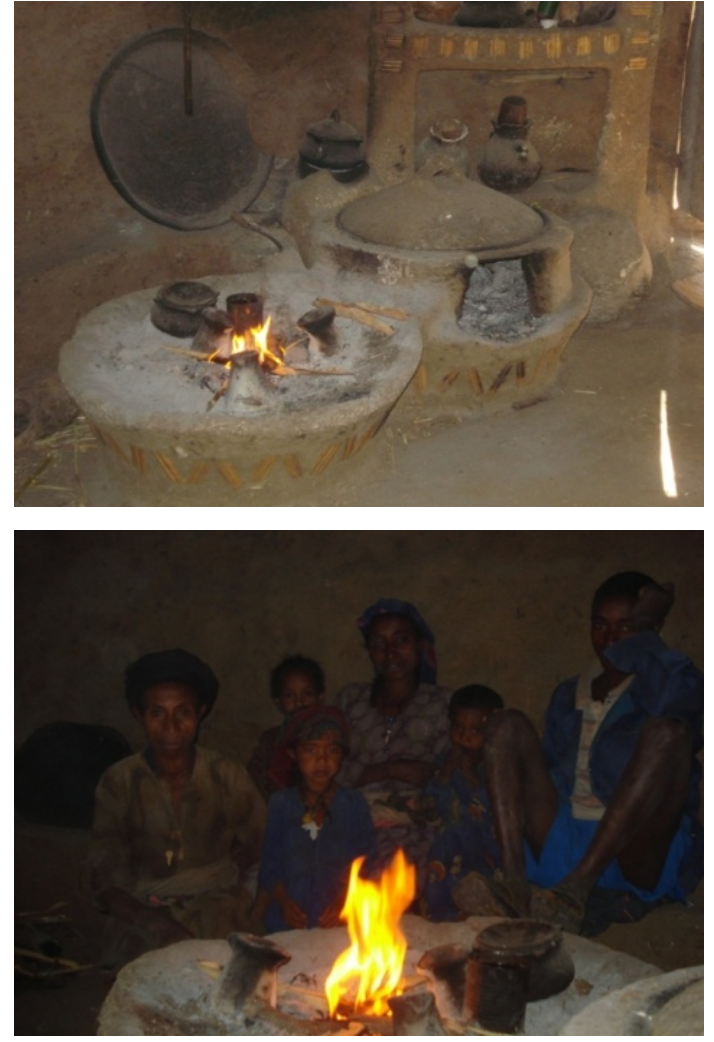

Fig. 2 Multiple functions of stoves in the rural community.

factors attributing to the inefficient use and causes of degradation as indicated below.

\subsubsection{Watershed Approach}

Across the country, watershed approach is used by the government extension services for rehabilitation of degraded areas and maximization of its productivity in the framework of food security and sustainable resource management. However, this approach has some gaps on the issue of empowerment of local community in decision making and on learning from the deep rooted indigenous practices, and it focuses on protection than utilization of resources. Accordingly, most of the communal areas are under strict enclosures to assure quick recovery of vegetation cover. However, this rule by the extension agents and kebele leaders has many undesired outcomes. First, many have sold some of their livestock due to shortage of animal food resulted from enclosures. In semiarid areas, rearing of livestock is more resilient to the adaption of climate change than crop production. 
Secondly, with the enclosure of the communal forest areas, the livestock pressure and land degradation have increased on cultivated areas, settlements and riverbanks (Fig. 3). Thirdly, many women and children are forced to travel long distance to collect fuel wood, and this also triggers resource use conflicts among the neighborhood communities. Fourthly, many of the craft people and poor women and children, who are diversifying their incomes due to free access to communal wood, are forced to drop and depend on relief food.

\subsubsection{Green Revolution}

Modern agricultural extension service focuses on the maximum yield per unit area using improved seed and artificial fertilizer. As in the case of Salayish, injera made from this improved crop varieties gets dry very quickly and therefore needs to be made fresh every day. This frequent preparation results in the use of more fuel wood than that is used to prepare injera from the local sorghum variety. This implies the need to consider multiple factors in needs and priorities of the community before introducing improved seeds.

\subsubsection{Investment Policy}

As in the case of Konso (Dekotu), the communal river banks are major sources of fuel wood, wild fruits, traditional medicine and reserve for traditional irrigation during irregular drought, as they are located in the highly malaria prone areas. However, due to the government policy of assigning river banks to investors, the community has cleared the vegetation to claim the ownership of land in the river banks. In other words, the fundamental cause of deforestation was defective government policy than the practice of traditional stoves.

\section{Local Innovation in Fuel Energy Saving Practices}

In this context, innovation can be referred as new discovery or modification of existing technology. In fact, every farmer (female/male) is an innovator to some degree, where some innovations are visible and others are invisible even for locals and probably not visible for outsiders. Considering the heterogeneity of the community at household level in wealth rank, food cultures and access to different biomass fuels, it is difficult to find two households who use traditional stoves for similar purposes, and on the level of community the differences are huge. This makes clear that the same standard technology can not be applied to the heterogeneous community and ecology. However, the basic principles or functions of the introduced technology might be the same. Accordingly, some of the local innovations observed in the study areas are highlighted.

(1) Minimizing smoke: In addition to the use of different types of trees branches that can easily burn with the minimal smoke, some women use reed pipes to ignite the flame to minimize the smoke irritations on their eyes (Fig. 4). Similarly, many of the traditional cottage houses have small holes on the corner of the house to escape the smoke. Yet, some individuals put

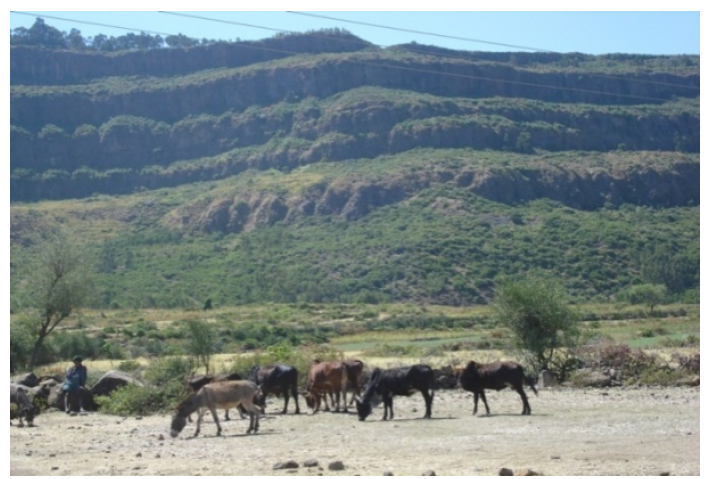

Fig. 3 Concentration of livestock and overgrazing.

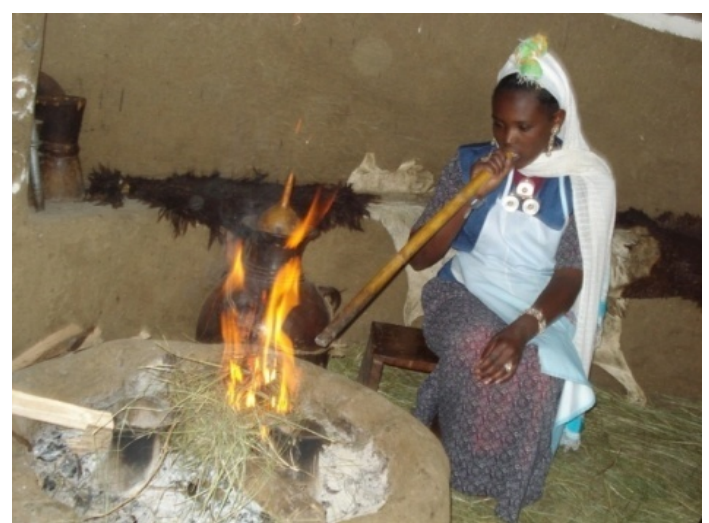

Fig. 4 Use of reed pipe to reduce smoke. 
water in a container in the outlet to reduce the risk of a fire (Fig. 5).

(2) Adaption of modern stoves: Modern improved cooking stoves were introduced by the non-governmental organization (NGOs) and government (Fig. 6). Unfortunately, the modern technology was not diffused in the community as expected due to at least two factors. First, it is expensive as cement is not locally available and second, different households can not use the standard technology with different cooking tools and fuel wood sources. However, the communities have learned the rational function of modern technology in conserving energy and minimizing smoke. Accordingly, they made their own stoves from soil and dung with different size for baking injera (near to the open stove) (Fig. 2).

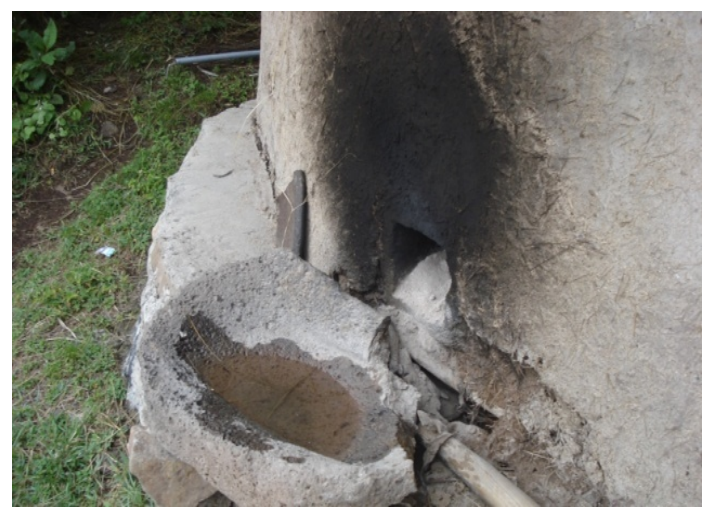

Fig. 5 External chimney with water.

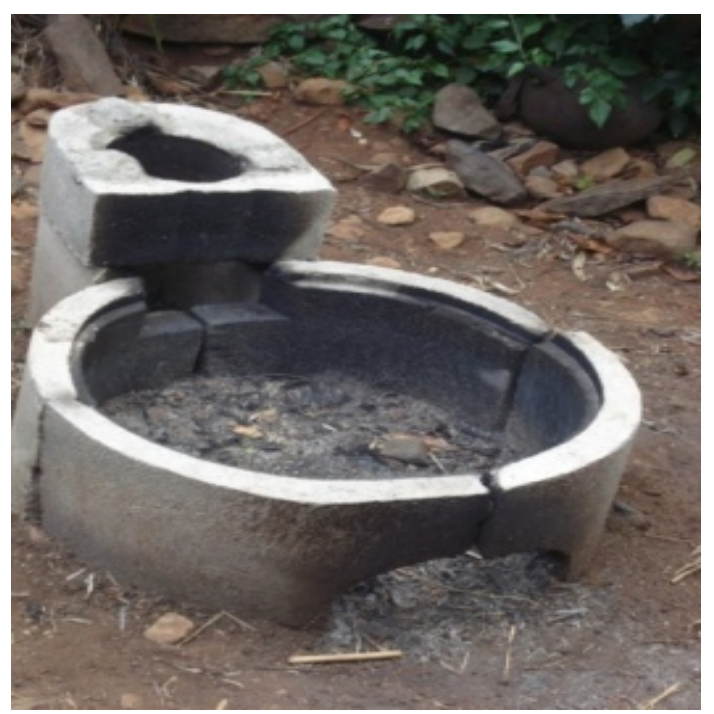

Fig. 6 Introduced stove.
(3) Combination of different crops: In the semi-arid areas, injera is prepared from sorghum as a stable food. Injera from sorghum is prepared every day or every other day depending on the family size, as it dries up quickly. One preparation demands one bundle of wood and some cattle dung. However, today some innovative women have started preparation of injera by combining $75 \%$ sorghum and $25 \%$ teff which does not dry up quickly, and a household can prepare food in every third day. This innovation has reduced the fuel wood demand of $30 \%-40 \%$. In addition to the nutritional value of combining the two crops, many have shifted cattle dung to soil fertility improvement. Currently, this practice is wide spreading in the semi-arid areas.

(4) Improving local stoves by women pottery: Different types of traditional clay made utensils for drink and food preparation (coffee/tea, wat, injera, araqe) were designed by the local women to be thicker. Gradually, female potters have reduced the thickness and modified the size of their products in response to the shortage of fuel wood and without compromising the food taste (Fig. 7). This local initiative is widespread among the women pottery in the rural areas. Similarly, the local craft people have potential of the joint experimentation and development of appropriate technology that addresses the needs and priorities of the community.

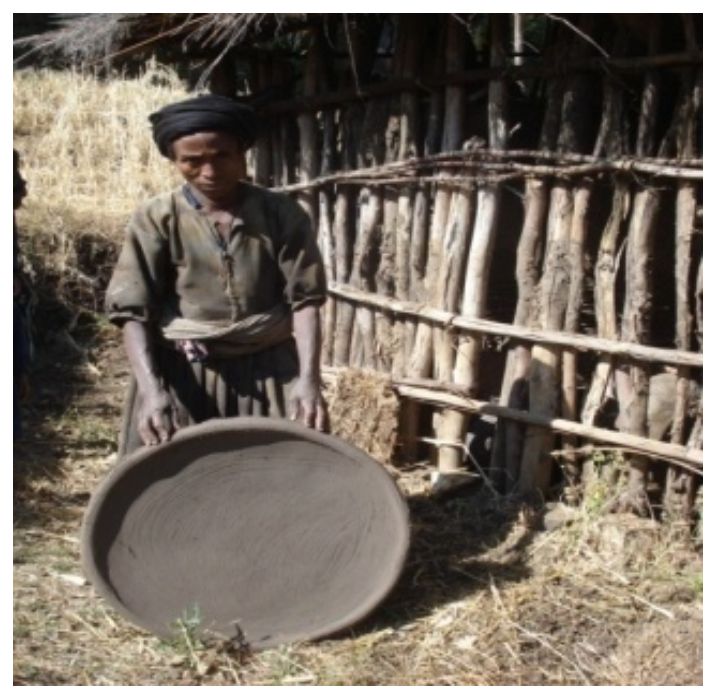

Fig. 7 The modified clay made stove. 
(5) Joint experimentation in improving stove chimney: The introduction of energy saving stoves played fundamental role in minimizing fuel wood consumption and reducing smoke. The introduce of improved stoves by the government extension services in the rural areas comes usually without attached chimney essential for reducing the smoke in the home. As a result, a health extension worker suggested that a pottery maker can design a chimney from clay that could be added to the existing model. After some experimentation with the diameter and length of the chimney, the pottery woman was able to produce a standard chimney with a diameter of $10 \mathrm{~cm}$ and length of $38 \mathrm{~cm}$, which also prevents fire accidents (Fig. 8). They set a price of 10 Birr for each chimney, have already sold to more than 200 households, and the demand is still very high.

(6) Improving the design of local beer processing: Many poor women are engaged in selling local beer, known as Arake. It is prepared by distillation process using bamboo. Traditionally, the bamboo used for distillation was relatively longer (one meter or more) and it requires too much fuel to distil Arake. However, the local craft man after some experimentation has found the optimal size of the bamboo is about $75 \mathrm{~cm}$, which demands relatively less fuel wood with the promising quality of Arake (Fig. 9).

(7) Land use changes from cropping to tree plantation: Many farmers in Doketu have converted one or more of their fragmented farming plots to tree plantations (Fig. 10). Usually, these plots are far from the homesteads and used to be under share cropping arrangements owned by the poor and women. This change of land use has also other benefits: (i) adaptation to recurrent drought and poor soil fertility with the deep roots; (ii) less labour demand and damage by wildlife or diseases, thus releasing household labour to be engaged on complementary activities, such as crafts, petty trade and daily wage labour in towns; (iii) availability of timber for local consumption and for sale. Timber has high demanded
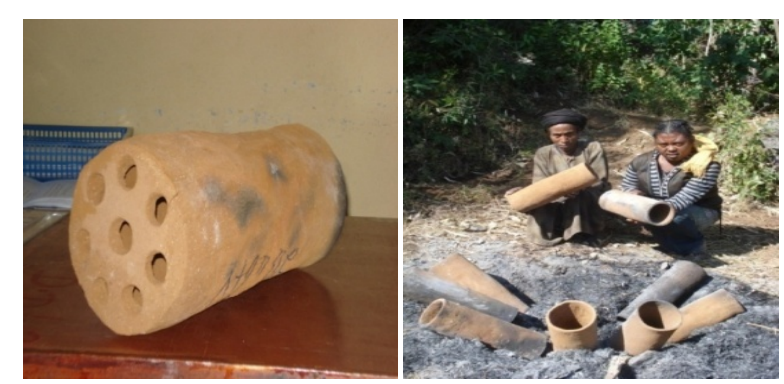

Fig. 8 Joint experimentation.

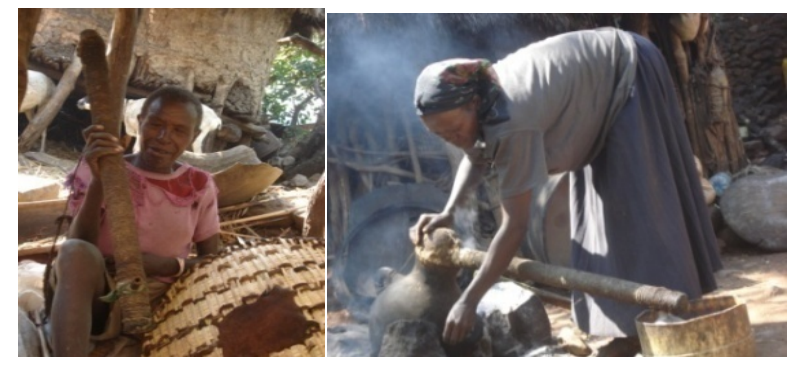

Fig. 9 Experiment with improved bamboo design.

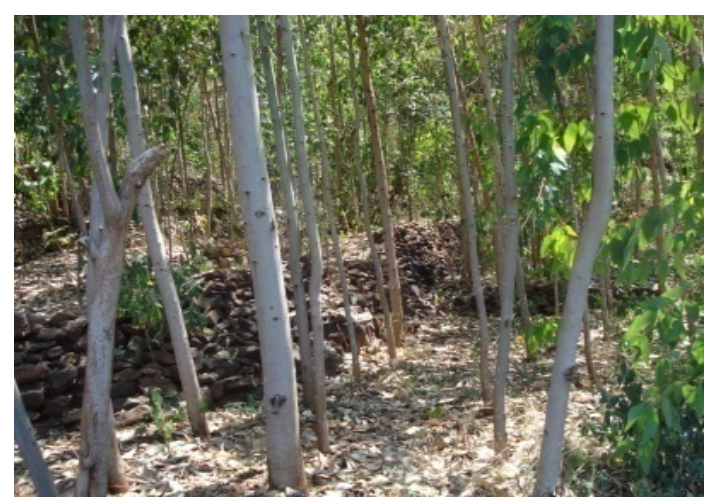

Fig. 10 Land-use change from annuals to perennials.

at a good price in both urban and rural areas. For example, from a small plot ( $0.2 \mathrm{ha}$ ) of the innovator farmer, up to 30,000 Ethiopian Birr (€1,125 at 2014 exchange rates) can be earned by selling trees that can grow in 3-4 years, which is profitable than crop production. This practice is slowly spreading in the study areas.

\section{Discussion}

Based on the results, the following major conclusions can be highlighted:

(1) Far from tragedy of commons: Traditionally, the communal grazing lands and wood land are managed by the knowledgeable and experienced elderly people. These communal resources have multiple functions 
and have a seasonal cycle for access and preservation. The communal wood land is also serving as a reserve during prolonged drought where community members are able to survive with the sale of fuel wood. Many poor women depend on the sale of wood (branches), while the craft people depend with free access to the branches. Unfortunately, such deep rooted experiences are not usually integrated in the modern or watershed approaches.

(2) Diversity and complexity of traditional stoves: The community has wider range of fuel sources for the preparation of different cultural food and drinks with different utensils. Moreover, the traditional stoves are practiced both indoors and outdoors. The indoor cooking usually uses dry wood and also serves as warming and lighting. The outdoor cooking usually is combined with looking after the children and small animals, drying up grain on the sun, threshing and discussions with neighbors on the fresh air. Moreover, preparation of food and drinks during farming activities, holidays or marriages is usually done in the outdoors together with neighbors. The ash from the traditional stove is used also as fertilizer around the homestead.

(3) Perceptions on time lost collection of fuel wood: In rural areas in general and pilot areas in particular, the collection of fuel wood is usually combined with farming activities, such as hoeing, weeding, guarding from wild life, harvesting and keeping livestock with division of labour in the household. For example, it was calculated that in average, women in Ethiopia spent up to $12 \mathrm{~h}$ per week collecting biomass fuel (wood/dung) for cooking. This was converted to monetary equivalent and found that a single woman spent daily about half USD dollar [15]. This simple calculation is not only exaggerated but also misleading, as this simple analysis does not consider the combining work in collecting the fuel wood, the free access to wood/dung, income generation and serves as a spring board in diversification of the poor household livelihood.
(4) Underestimation of changes in rural areas: In both pilot areas, cottage and corrugated iron made houses are common. The corrugated iron made houses accounts $60 \%$ to $70 \%$ used to be sign of economic status and modernization. Moreover, the modern corrugated iron has windows with a better air circulation and minimal smoke.

(5) Priorities in saving energy: Many of the poor women in rural Ethiopia are highly depending on the sale of Areke (distillation process) as means of livelihoods and the highest fuel consuming activity. Yet, none of the introduced improved cooking stoves have addressed the problem, except the local innovation.

(6) Vulnerability to inefficient fuel energy use: Large community is blamed for inefficient energy use, deforestation and land degradation. However, the case study clearly indicated that with the introduction of watershed approach geared to protection of the wood land and marginalization of the customary institutions, the community were encounter with shortage of fodder, livestock pressure on the other land uses (cultivated, settlement, river banks and grazing areas), many women and children were forced to travel long distance to collect fuel wood and this also triggered resource use conflicts among the neighborhood communities. Moreover, many poor women depending on sale of fuel wood to diversify their livelihood were forced to depend on safety net, and similarly many craft people quit their job and depend on safety nets. Similarly, the introduction of improved seed with the green revolution has trigger to use more fuel in preparation of the food, while investment policy on irrigation has accelerated deforestation in the riverbanks.

(7) Local innovation: The local community use wider range of local innovation and practices in the efficient use of energy. Such as, the use of reed pipes to ignite the flame, adaption of modern stove with local material, combination of different local crops in food preparation to prolong the interval of fuel use, improving the apparatus of local beer processing to 
consume less energy, joint experimentations with local craft people and change of land use from crop to wood land, are some to be mentioned. Hence, the focus only on introduced technologies is not only incomplete, but also marginalizes the community competence to experiment and innovate to solve the energy related problems.

\section{Conclusions and Recommendations}

The traditional stoves are dominant practices due to flexibility and multi-functionality. Moreover, the local innovations are attributed to efficient use of fuel wood and are minimizing smoke, while the inefficient use of biomass energy is also attributed to external factors. This implies the need for joint experimentation for synergetic effect, consideration of the indirect energy saving, minimizing smoke innovative practices and capitalization of participatory approaches to minimize external shocks attributed to inefficient fuel energy uses. Moreover, the use of biomass fuel with traditional stove is a complex and divers system, where the interface of the communal resource management, socio-economic settings and customary institutions play a fundamental role. Hence, improving biomass energy efficiency needs to shift from technical approach to the consideration of synergy between the different sub-systems with the empowerment of the community in decision making.

The diffusion of standard technologies with the principle of one fit to all (adoption) under heterogeneous community seems as a short cut and less sustainable. However, already the principles of improved cooking stove have been adapted to their local conditions. Hence, the international and national initiatives on diffusion of improved cooking stove need to have some shift from standard technology development to function or principle based development.

\section{Acknowledgments}

The deep gratitude goes to the case study community and work grassroots of NGOs, who so generously shared their knowledge and experiences. And also thanks Addis Ababa University and the Department of Geography and Environmental Studies for creating enabling environment to conduct the research.

\section{References}

[1] World Health Organization (WHO). 2015. "Household (Indoor) Air Pollution.” Accessed March 1, 2015. http://www.who.int/indoorair/en/.

[2] Japan International Cooperation Agency (JICA). 2011. "Energy Policy of Ethiopia." Minstry of Water and Energy, Country Report, TICA, Tokyo International Centre. Accessed July 5, 2011. https://eneken.ieej.or.jp/data/3959.pdf.

[3] Bielecki, C., and Wingenback, G. 2014. "Rethinking Improved Cook Stove Diffusion Programs: A Case Study of Social Perceptions and Cooking Choices in Rural Guatemala.” Energy Policy 66: 350-8.

[4] International Energy Agency (IEA). 2012. World Energy Outlook. Paris: IEA.

[5] Hutton, G., Rehfuess, E., and Tediosi, F. 2007. "Evaluation of Costs and Benefits of Interventions to Reduce Indoor Air Pollution.” Energy for Sustainable Development 11 (4): 34-43.

[6] Kebede, B., Bekele, A., and Kedir, E. 2002. "Can the Urban Poor Afford Modern Energy? The Case of Ethiopia.” Energy Policy 30 (11-12): 1029-45.

[7] Lewis, J. J., and Pattanayak, S. K. 2011. Determinants for Stove Adoption and Fuel Switching: A Systematic Review. Durham, NC, USA: Duke University.

[8] Arvidson, A. 2006. "The Global Energy Implication of MDGs.” Recommend Vol. 3, NR4, a Newsletter of the Commend Initiative for Energy, Environment and Development. Accessed January 2006. http://www.energycommunity.org/reCOMMEND/reCom mend4.pdf.

[9] Eshetu, A. A. 2014. "Factors Affecting the Adoption of Fuel Efficient Stove among Rural Households in Borena Woreda, North Central Ethiopia.” International Journal of Energy Science 4 (5): 141-54.

[10] Kooser, S. H. 2014. "Clean Cooking: The Value of Clean Cookstoves in Ethiopia.” Journal of Environmental and Resource, Economics at Colby 1 (1). http://digitalcommons.colby.edu/jerec/vol01/iss01/3.

[11] Malla, S., and Timilsina, G. R. 2014. Household Cooking Fuel Choice and Adoption of Improved Cookstoves in Developing Countries: A Review. Policy Research Working Paper No. WPS 6903. 
[12] Gebreegziabher, Z., Mekonnen, A., Kassie, M., and Kohlin, G. 2012. "Urban Energy Transition and Technology Adoption: The Case of Tigrai, Northern Ethiopia.” Energy Economics 34 (2): 410-8.

[13] Kojima, M., Bacon, R., and Zhou, X. 2011. Who Uses Bottled Gas? Evidence from Households in Developing Countries. Policy Research Working Papers No. WPS 5731, the World Bank, Washington, DC.

[14] Masera, O. R., Saatkamp, B. D., and Kammen, D. M.
2000. "From Linear Fuel Switching to Multiple Cooking Strategies: A Critique and Alternative to the Energy Ladder Model.” World Development 28 (12): 2083-103.

[15] Yeraswork, A., and Ezana, A. 2010. The Araque Dilemma: The Socioeconomics of Traditional Distilled Alcohol Production, Marketing and Consumption in Ethiopia. Addis Ababa, Ethiopia: Forum for Social Studies. 